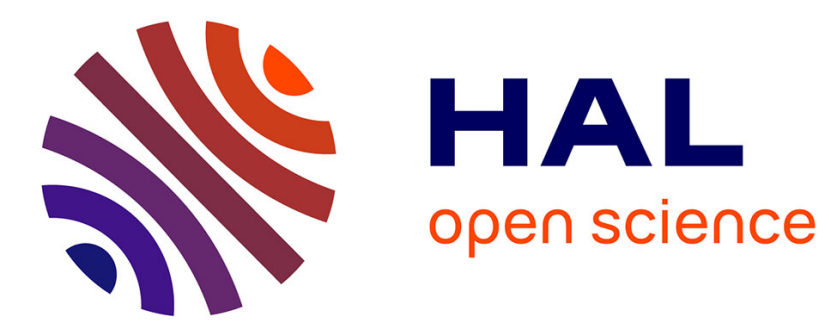

\title{
Supermarkets vs. FIFO Lanes: A Comparison of Work-in-Process Inventories and Delivery Performance
}

Denis Wiesse, Christoph Roser

\section{To cite this version:}

Denis Wiesse, Christoph Roser. Supermarkets vs. FIFO Lanes: A Comparison of Work-in-Process Inventories and Delivery Performance. IFIP International Conference on Advances in Production Management Systems (APMS), Sep 2016, Iguassu Falls, Brazil. pp.651-658, 10.1007/978-3-319-51133-

7_77. hal-01615758

\author{
HAL Id: hal-01615758 \\ https://hal.inria.fr/hal-01615758
}

Submitted on 12 Oct 2017

HAL is a multi-disciplinary open access archive for the deposit and dissemination of scientific research documents, whether they are published or not. The documents may come from teaching and research institutions in France or abroad, or from public or private research centers.
L'archive ouverte pluridisciplinaire HAL, est destinée au dépôt et à la diffusion de documents scientifiques de niveau recherche, publiés ou non, émanant des établissements d'enseignement et de recherche français ou étrangers, des laboratoires publics ou privés.

\section{(c)(1)}

Distributed under a Creative Commons Attribution| 4.0 International License 


\title{
Supermarkets vs. FIFO Lanes: A Comparison of Work-in-Process Inventories and Delivery Performance
}

\author{
Denis Wiesse ${ }^{1}$ and Christoph Roser ${ }^{2}$ \\ 1 Robert Bosch GmbH, Rutesheim, Germany \\ denis.wiesse@gmail.com \\ 2 Karlsruhe University of Applied Sciences, Karlsruhe, Germany \\ christoph.roser@hochschule-karlsruhe.de
}

\begin{abstract}
Pull production is a key element for a lean manufacturing system. In pull production, buffer inventories between two processes can be implemented either through a FIFO lane as part of a kanban loop, or through a supermarket, in which case the value stream is split into two different kanban loops. This paper compares the usage of FIFO lanes and supermarkets with respect to the work-in-process inventory needed to achieve a similar delivery performance. The results clearly show that there is only a minor difference in inventory between the usage of FIFO lanes and supermarkets.
\end{abstract}

Keywords: Inventory reduction · FIFO - Supermarket · Pull · Delivery Performance · WIP

\section{Introduction}

Pull production is a key element for a lean manufacturing system. Kanban systems are commonly used to implement pull production. A pull system can consist of multiple kanban loops, each of which can include multiple processes along the value stream. The buffer inventory between two processes can be implemented either through a FIFO lane as part of a kanban loop, or through a supermarket, in which case the value stream is split into two different kanban loops.

Buffer inventories are necessary to decouple fluctuations between processes, which may stem from technical problems, cycle-time variations, unsteady material delivery, and many other reasons. The larger the buffer, the better the decoupling of fluctuations.

Yet, buffer inventories also cause significant costs. Industry usually calculates the cost due to the bound capital, sometimes also including storage and handling cost. What is usually not included is the delay of information through the material flow (e.g., detecting flawed parts too late), obsolescence cost, deterioration over time, etc. [1]. One of the key insights in lean manufacturing is to realize the significance of these inventory related costs and to pursue inventory reduction as part of the continuous improvement process. 
When establishing a pull production, between each pair of sequential processes the designers have the option to add a FIFO lane as part of a bigger kanban loop, or to add a supermarket and split the flow into two kanban loops (see Fig. 1 below for the example used within this analysis). There are no fixed rules on when to use a FIFO and when to use a supermarket, although there are recommended guidelines [2]. In general, it is recommended to use a FIFO lane, which is much easier to manage, unless there are compelling reasons to go for a supermarket.

This paper compares the usage of FIFO and supermarket with respect to both work-in-process and delivery performance. The goal is to determine if a supermarket or a FIFO requires less work-in-process inventory for the same delivery performance. Is it better for inventory to have a supermarket or a FIFO between processes? This paper is based on a master thesis by one of the authors, supervised by the other author [3]. To the best of our knowledge such a comparison has not yet been undertaken before. However, before we go into the details of the analysis, we first need to define the terms as used within this paper.

\subsection{Definition of Push and Pull}

While the term pull is used almost everywhere in lean manufacturing, the definition of pull is often quite different. It is only agreed that pull is the opposite of push. Powell and Arica recently surveyed the literature and found around 30 definitions in production management, supply chain management, and project management [4]. Within this paper we follow the, in our view, most compelling definition by Hopp and Spearman "A pull production system is one that explicitly limits the amount of work in process that can be in the system. By default, this implies that a push production system is one that has no explicit limit on the amount of work in process that can be in the system" [5].

\subsection{Definition of FIFO Lanes}

A FIFO lane stands for First-In, First-Out. This automatically gives the first part of a definition, which requires that the parts leave in the same sequence as they arrive [6]. However, since the FIFO lane is part of a pull system, it needs to incorporate the definition of pull from above and needs to have an upper limit on inventory. This brings us to our own definition of a FIFO lane: "A FIFO lane is an inventory where the parts leave in the same sequence as they arrive. There is a limit to the maximum inventory. If the FIFO lane is full, the receding process stops".

\subsection{Definition of Supermarkets}

A supermarket differs from a FIFO lane in that the material flow and the information flow splits. In a FIFO lane, the material automatically includes the information on what the material is. If material is removed from a supermarket, 
the information on the part goes back to the beginning of the kanban loop to replenish the part. This information is the kanban. A supermarket consists of multiple parallel FIFO lanes, one for each material type that is handled by the supermarket. As with the FIFO lane, the supermarket has an upper limit on the number of parts, although this is usually maintained through the number of kanban in circulation and not implemented separately. This leads us to our definition of supermarket "A supermarket is an inventory where the parts are stored separately by type. The parts by type leave in the same sequence as they arrive. When a part leaves, information is sent back along the value stream to replenish the part".

\subsection{Definition of Work-in-Process Inventory}

The definition of work in process is rather straightforward. "Work in process (WIP) is the amount of material - measured in pieces, or by weight, volume, or value - for one part type or for multiple part types combined for a certain section of the value stream".

Depending on the situation, this may or may not include the supermarket inventory. For our purposes, we do include the supermarket inventory to get a reasonable comparison between a system with a FIFO and a system with a supermarket. For pull systems, this quantity has to be limited. In kanban systems, it is limited through the number of kanban [7].

\subsection{Definition of Delivery Performance}

Delivery performance aims to measure the reliability of satisfying customer orders, both quantity-wise and timewise (i.e., in full on time) [8]. Disagreement exists in industry if a too-early delivery is counted as good or not, which tolerances are allowed around the scheduled delivery date, and if the scheduled delivery date is the first date requested by the customer or the date agreed on between customer and supplier. For our purposes, we define delivery performance as follows: "Percentage of the customer orders that can be fulfilled on time and in full".

\section{Analysis}

For the analysis, a simulation environment was used. This allows for an easy gathering of data and comparison of different systems.

\subsection{Analyzed System}

For a stringent comparison, we analyzed a simple system consisting only of two processes, P1 and P2, and a single product variant. Two different systems were compared, where either a single kanban loop includes both processes with a FIFO in between, or the system is split into two different kanban loops. This is shown 
a)

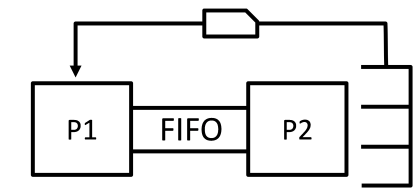

b)

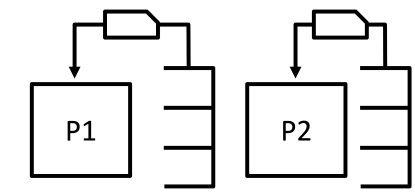

Fig. 1. Two processes connected through FIFO within one kanban loop (a) or split into two different kanban loops using a supermarket (b)

in Fig. 1 below as a) and b) respectively. For the diagrams, we used standard value stream mapping notation as introduced by Rother and Shook [9].

Intuitively, a supermarket has more inventory than a FIFO lane. However, having a longer replenishment time in a) requires one large supermarket at the end, whereas the two separate loops in b) each have a shorter replenishment time and hence both supermarkets require less material for a similar delivery performance. In the following, we will call a) a single-loop system, and b) a double-loop system.

\section{$2.2 \quad$ System Settings}

The systems in Fig. 1 have been compared using different settings of cycle times and customer demand to represent a variety of different situations that may be expected in industry. Since the durations are all relative to each other, no time units are required, although for simulation purposes, minutes were used. Table 1 gives an overview of the tested systems. We examined systems that had both equal cycle times and unequal cycle times. Additional systems were tested in the original master thesis with similar results [3]. The systems have been simulated using the commercial Simul8 software package.

Table 1. Overview of the mean time between parts of the simulated systems. All times were exponentially distributed

\begin{tabular}{cccc}
\hline \multirow{2}{*}{ System } & Cycle Time Cycle Time & Customer \\
& P1 & P2 & Takt \\
\hline 1 & 10 & 10 & 12 \\
2 & 10 & 9 & 12 \\
\hline
\end{tabular}

All times were exponentially distributed. The duration of each simulation exceeded 8,000 parts, excluding a warm-up period of 300 parts. Each simula- 
tion was repeated at least 51 times to verify the accuracy of the results using confidence intervals.

All systems have been simulated using a wide range for the number of kanban both for a single-loop and a double-loop system to determine the relation between the WIP and the delivery performance. For example, the single-loop system 1 has been simulated with any number of kanban cards between 1 and 40 in combination with any number of FIFO capacity between 1 and 40. In total, 1,600 simulations have been repeated 51 times, each merely for the single-loop system with equal cycle times and a slow customer takt. The double-loop system 1 has been simulated with any number of kanban cards between 1 and 30 for each loop (i.e., a total of 900 simulations, all of them repeated 51 times for accuracy).

Similar simulations were performed for system 2 both for the single-loop and double-loop system. Simulations of additional systems can be found in [3]. In all cases, the best combination of WIP and delivery performance were determined, as well as the expected results, using a standard kanban formula. Overall, in excess of 300,000 simulations using weeks of computation time were used to derive the data below.

\section{Analysis Results}

\subsection{System 1 - Equal Cycle Time}

All combinations of kanban cards between 1 and 40, and FIFO capacity between 1 and 40, for the single loop as well as all combinations of number of kanban cards for both loops between 1 and 30 have been simulated. Both the delivery performance and the WIP have been measured for each simulation. Fig. 2 shows the best combination with minimal WIP for any delivery performance between 0 and $100 \%$ for both the single-loop and the double-loop system.

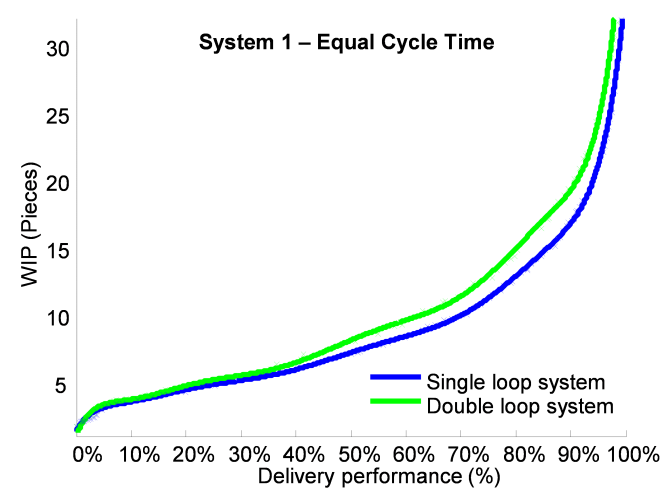

Fig. 2. Delivery performance vs. WIP for system 1 with equal cycle times 
As expected, a higher WIP through a higher number of kanban and FIFO capacity improves the delivery performance. The relation is not linear, and a disproportionally larger inventory is needed to achieve a near-perfect delivery performance. The optimal combination of WIP and delivery performance for both the single-loop and the double-loop system looks very similar. Additional statistical analysis, however, confirms that the two curves are indeed statistically significant different for delivery performances in excess of 30\% [3]. This analysis shows that the single-loop system a) in Fig. 1 requires less WIP to achieve the same delivery performance as the alternative double-loop system b).

\subsection{System 2 - Unequal Cycle Time}

The second system is similar to system 1, except that the second process P2 now has a faster mean cycle time of nine time units instead of ten time units. Fig. 3 shows again the best combination of WIP and delivery performance for the single-loop and double-loop system. Again, the single-loop system requires statistically significant less WIP for the same delivery performance compared to the double-loop system.

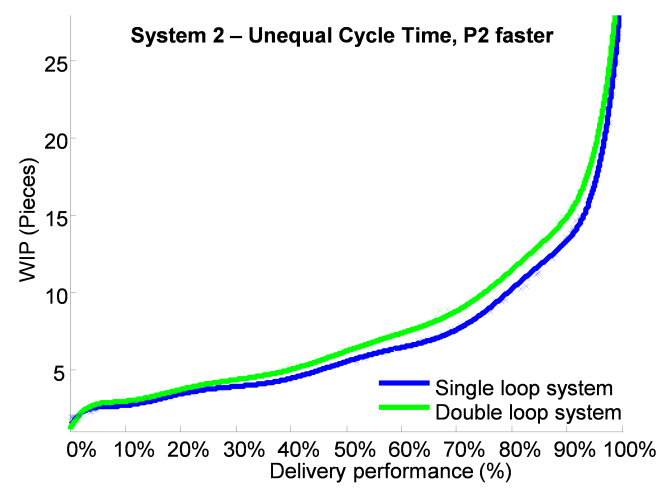

Fig. 3. Delivery performance vs. WIP for system 2 with unequal cycle time, P2 faster

\section{Interpretation of Results}

In all simulated systems (and additional systems found in [3]), the single-loop system requires less WIP for the same delivery performance. These results are statistically significant for delivery performances above $50 \%$. This means that since most companies have a delivery performance above $40 \%$, these results are statistically significant.

The single-loop system is able to "work ahead" more during times of low demand. Fig. 4 shows the material distribution for times with low or no demand. 
In the single-loop systems, all kanban would eventually end up with material in the supermarket, and all WIP would be concentrated in the supermarket. If demand would pick up again, the single-loop system would be theoretically able to deliver products equivalent to all kanban cards immediately.

a)

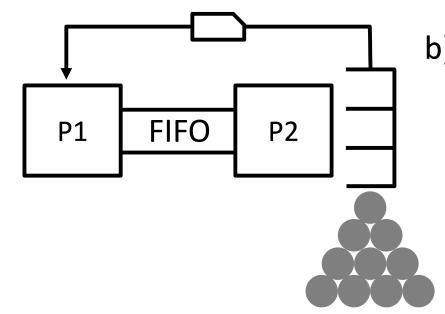

b)

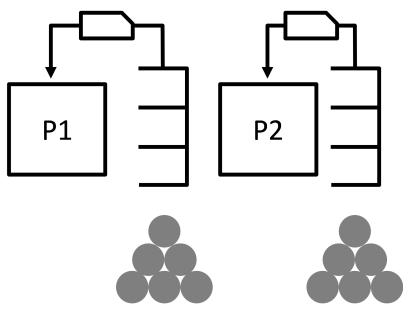

Fig. 4. WIP locations during low demand

A double-loop system, however, would have only part of the material in the final supermarket, and part of the material in the intermediate supermarket. The exact allocation of the WIP depends on the number of kanban cards in each loop. Hence, the double-loop system would theoretically be able to deliver only the material equivalent to the last kanban loop. If the demand would be higher, material from the intermediate supermarket would first have to pass through process P2.

Since delivery performance is a benefit but WIP is a cost, a system that has better delivery performance for the same WIP (or the same delivery performance for less WIP) performs better. In all tested systems, the single-loop system was statistically significant better than a double-loop system.

However, statistically significant does not necessarily mean practically significant! The single-loop system would come at a cost of potentially quite uneven material distribution as shown in Fig. 4 part a) above. Besides reduction in WIP, however, lean manufacturing also emphasizes a level production. The idea of having a pile of material at one point but none at the other goes against lean thinking. It is difficult to quantify, but it is definitely one reason against using a single-loop system despite lower WIP.

For a delivery performance of around 95\%, the single-loop system required about $20 \%$ less WIP in both cases. Hence, there would be a small benefit in WIP. Yet, these results were achieved only after exhaustive testing of all possible combinations of number of kanban and FIFO capacities. In reality, such an exhaustive test is usually not possible. Instead, the number of kanban cards are estimated using either gut feeling or a kanban formula - which by itself is also nothing but a rough estimation with a significant margin of error. For the FIFO capacity, an expert estimate is the most common way in industry, which is also quite uncertain. Overall, it is unlikely that a real line will get the "just right" number of kanban cards and FIFO capacity to benefit from these optimal conditions. 
As a conclusion, using a single-loop has a small advantage in respect to WIP and delivery performance. However, in practice there are many other considerations that can easily overrule the small WIP benefit of a single-loop system.

\section{References}

1. Richardson, H.: Control Your Costs Then Cut Them. Transp. and Distrib. 36(12), 94-96 (1995)

2. Roser, C., Nakano, M.: Guidelines for the Selection of FIFO Lanes and Supermarkets for Kanban-Based Pull Systems - When to Use a FIFO and When to Use a Supermarket. In: Umeda, S., Nakano, M., Mizuyama, H., Hibino, H., Kiritsis, D., Cieminski, G.v. (eds.) Advances in Production Management Systems: Innovative Production Management Towards Sustainable Growth. No. 460 in IFIP Advances in Information and Communication Technology, Springer International Publishing (2015)

3. Wiesse, D.: Analyse des Umlaufbestandes von Verbrauchssteuerungen in Abhängigkeit von der Nutzung von Supermärkten und FiFo-Strecken. Ph.D. thesis, Karlsruhe University of Applied Sciences, Karlsruhe (2015)

4. Powell, D., Arica, E.: To Pull or Not to Pull: A Concept Lost in Translation? Am. J. Manag. 15(2), 64 (2015)

5. Hopp, W.J., Spearman, M.L.: To pull or not to pull: what is the question? Manuf. Serv. Oper. Manag. 6(2), 133-148 (2004)

6. Marchwinski, C., Shook, J.: Lean Lexicon: A Graphical Glossary for Lean Thinkers. Lean Enterprise Institute (2003)

7. Karmarkar, U.S.: Kanban Systems. Tech. rep., University of Rochester, Rochester (1986)

8. Rao, M.C., Rao, P.K., Muniswamy, V.V.: Delivery Performance Measurement in an Integrated Supply Chain Management: Case Study in Batteries Manufacturing Firm. Serbian J. Manag. 6(2), 205-220 (2011)

9. Rother, M., Shook, J.: Learning to See: Value Stream Mapping to Add Value and Eliminate Muda. Lean Enterprise Institute (2003) 